\title{
EREBEA
}

Revista de Humanidades

y Ciencias Sociales

Núm. 5 (2015), pp. 325-351

ISSN: 0214-0691

\section{UNA APROXIMACIÓN AL MERCADO Y FUERZA DE TRABAJO DE MARRUECOS}

\author{
Israel Macías Llaga \\ Universidad de Huelva
}

Resumen

Marruecos ha triplicado su población en menos de medio siglo, pasando de 10 millones de habitantes registrados en 1960 a más de 30 millones en la actualidad. Esta explosión demográfica o fenómeno de "baby boom", unida a las debilidades inherentes de su mercado de trabajo, explica la problemática situación en la que se encuentran muchos marroquíes en edad de trabajar: economía informal e ilegal, una gran elenco de carestías o, quizás el más "alentador", la tesitura de la emigración.

En esta investigación se analizarán los principales indicadores geográficos que vertebran y explicitan algunas de las caras del reto demográfico que enfrenta al gobierno de Marruecos, como son la explotación infantil, la participación de la mujer en el mercado de trabajo, el analfabetismo, el peso del sector primario en la economía y la emigración.

Palabras Clave

Marruecos; Explosión demográfica; Fuerza de trabajo; Mercado de trabajo; Educación.

Fecha de recepción: 10 de febrero de 2015 Fecha de aceptación: 30 de octubre de 2015

\section{AbSTRACT}

Morocco has tripled its population in less than half a century, from 10 million people registered in 1960 to over 30 million today. This population explosion or "baby boom" phenomenon, together with the inherent weaknesses of its labour market, explain the problematic situation of many Moroccans of working age: an informal and submerged economy, large-scale food shortages, and perhaps most "promising" of all, the choice of emigration.

This study analyses the main geographical indicators that reveal and make explicit some of the faces of the demographic challenge facing the Moroccan government, such as child labour, the participation of women in the labour market, illiteracy, the weight of the primary sector in the economy, and emigration.

KEYWORDS

Morocco; Demographic explosion; Workforce; Labour market; Education. 



\section{INTRODUCCIÓN}

Uno de los principales problemas que reta a la actual estructura socioeconómica marroquí podría formularse de la siguiente manera: el crecimiento demográfico experimentado por Marruecos en los últimos 50 ańos no ha corrido en paralelo a la mejora de su fuerza y mercado de trabajo. La naturaleza de esta problemática de espinosa solución para cualquier territorio que atravesase la misma situaciónlanza a la política económica del gobierno alauita por escarpados caminos. Pero, efectivamente, el reto demográfico es ineludible, sobre todo si tomamos en consideración que Marruecos ha pasado de tener 10 millones de habitantes en 1960 a superar los 30 millones en la actualidad, mientras que los indicadores de desarrollo humano (IDH) siguen situándolo dentro del grupo de países en vías de desarrollo.

El fenómeno de "baby boom" que experimentó este territorio entre los años 50 y 60 del siglo pasado, sumado a la debilidad de su mercado de trabajo, donde encontramos en el último trimestre de 2012 una tasa de actividad (TA $)^{1}$ del 49\% (Haut Commissariat au Plan, Marruecos 2013), ofrece pocas alternativas a la población marroquí. Ente las más comunes: economía informal e ilegal, una gran elenco de carestías o, quizás el más "alentador", la tesitura de la emigración. Y aunque el margen de desolación que dejan tras de sí estas vicisitudes entre en sintonía con las de algunos países musulmanes del Mediterráneo (Egipto, Argelia, Siria, Túnez, Líbano, Jordania o Palestina), se vuelven duramente angustiosas cuando las comparamos con los países que integran la Unión Europea.

En este capítulo haremos un recorrido por los principales indicadores geográficos que vertebran y explicitan algunas de las características más sobresalientes del mercado y la fuerza de trabajo en Marruecos:

1 El departamento de Estadística del Haut Commissariat au Plan (HCP) de Marruecos define la tasa de actividad (TA) como el porcentaje de población activa (PA) respecto a la población total. $\mathrm{Al}$ mismo tiempo, tanto para el cálculo de la PA como para el de la TA se toman en cuenta aquellas personas que tienen 15 ańos o los superan, sin establecer ningún límite a la longevidad de las personas. En España, por ejemplo, el Instituto Nacional de Estadística (INE) calcula este mismo parámetro tomando como referencia las personas que se encuentran ente los 15 y los 65 ańos de edad. Es muy importante para el análisis comparativo de los mismos, en consecuencia, reparar en estas vicisitudes técnicas. Para una mayor información sobre este asunto, remitimos al lector a la Web del HCP, donde encontrará las respectivas indicaciones técnicas: http://www.wmaker.net/ myhcp2011/glossary/Activite-Emploi-et-Chomage gi2090.html 
- La explotación infantil, erradicada hace años en la Unión Europea pero de tremenda actualidad en Marruecos.

- La oculta y precaria participación de la mujer en la vida económica del país, vinculada sobre todo a los sectores más desfavorecidos como la industria textil o el sector agrícola, por no hablar de la predestinación social que la cultura, religión y la política marroquí determina para el alma femenina.

- La elevada tasa de analfabetismo, que aleja a Marruecos considerablemente de los países industrializados modernos.

- El empleo informal e ilegal, cuyas cifras se disparan en Marruecos hasta el punto de representar cerca del $50 \%$ de la totalidad del empleo.

- El peso del sector primario en la economía, donde el PIB agrario llega a representar entre el 15 y el 20\% del PIB general.

- Y, por último, el problema de la emigración y de los principales destinos del marroquí emigrante.

\section{Aproximación a la fuerza de trabajo marroquí}

\subsection{Evolución de la población}

En Marruecos conviven desde hace algunos siglos dos tipos de grupos étnicos: los árabes (aproximadamente un 60\%), que viven principalmente en las ciudades, y los bereberes (cerca del 40\%), que habitan sobre todo en las montañas y en el campo. Éstos últimos representan una antigua población perteneciente a un conjunto de etnias autóctonas del Magreb. Actualmente éstos se dividen en tres grupos distintos (Masmuda, Sanhaya y Zenata) y hablan tres dialectos diferentes ${ }^{2}$.

En el nuevo milenio, según el último censo oficial ${ }^{3}$ realizado en 2004 por el Haut Commissariat au Plan (HCP), donde precisamente se inscribe el Centro Nacional de Estadística de Marruecos, la población marroquí ascendía a 29.680.069 de habitantes, de los que un 55,1\% correspondía a población urbana, un 50,7\% representaba la población femenina, situándose la densidad de población alrededor de los $64,8 \mathrm{hab} / \mathrm{km}^{2}$. Además, el HCP estima que el conjunto de la población total sobrepasará en 2014 los 32 millones de habitantes, de los cuales más de 16,5 millones representan a la población total femenina. En la siguiente gráfica podemos

2 Sería imposible detallar con rigurosidad en este espacio la naturaleza histórica de los asentamientos de la población que en la actualidad habita en la geografía de Marruecos. Para una mayor información al respecto remitimos al lector a la magnífica obra de Víctor Morales Lezcano, Historia de Marruecos. De los origenes tribales y las poblaciones nómadas a la independencia y la monarquía actual. Madrid: La Esfera de los Libros, 2006.

3 En Marruecos la publicidad de los censos de población ha seguido una periodicidad irregular, aunque la diferencia con Espańa, que los publica cada 10 ańos, es mínima. La serie histórica de censos de población en Marruecos es la siguiente: 1960, 1971, 1982, 1994 y 2004. Más información sobre la metodología, regularidad, publicidad, etc. del censo de población puede obtenerse directamente en la siguiente web del Haut Commissariat au Plan (HCP): http://www.hcp.ma/RecensementGeneral-de-la-Population-et-de-l-Habitat a92.html 
observar el contraste entre la evolución de la población marroquí —a partir de las proyecciones del $\mathrm{HCP}$ - y la española — según los datos y proyecciones del Instituto Nacional de estadística (INE) — desde 1960 hasta nuestros días:

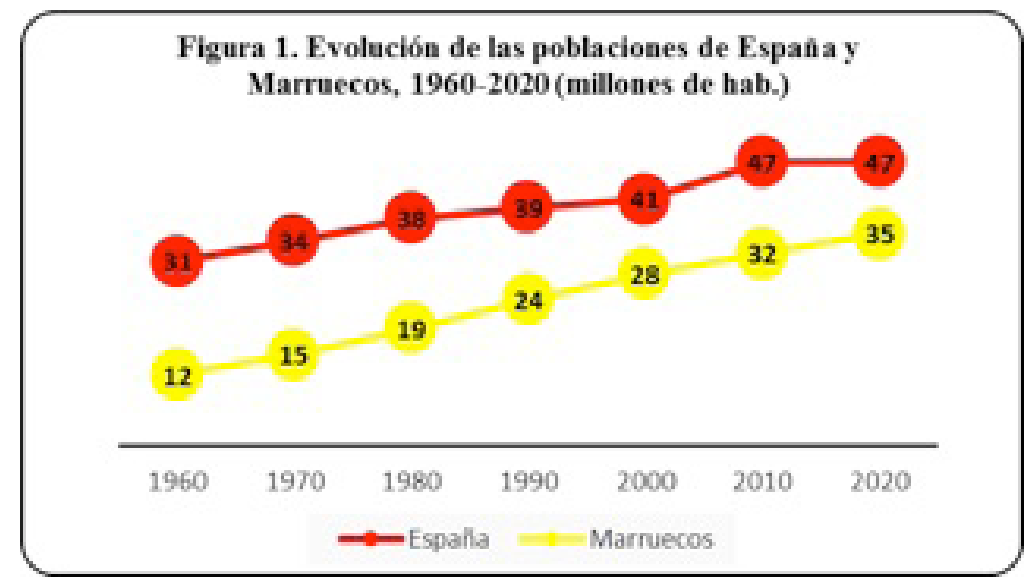

Fuente: Haut Commissariat au Plan (Marruecos) e INE (España). Elaboración: I. Macías, 2014

A simple vista, parece que las cifras irán aumentando levemente en los próximos ańos para la población de Marruecos. Las razones que explican este crecimiento de la población son múltiples, aunque quizás la más reseñable pueda deducirse del fenómeno del "baby boom" que experimentó este territorio entre los años 50 y 60 (Figura 2), en consonancia con el experimentado por el resto de países árabes del mediterráneo, el conjunto de países africanos y, por contra, en total discordancia con la mayoría de países que integran la Unión Europea (con una dinámica demográfica diferente, es decir con menos natalidad).

El crecimiento vegetativo se ha beneficiado no solamente de una importante tasa de fecundidad sino también de la mejora de las condiciones sanitarias que han presentado el conjunto de países árabes del mediterráneo (Aita, 2008: 23). Sin embargo, la tasa bruta de natalidad (TBN) de Marruecos (Figura 3) muestra una clara tendencia descendente, sobre todo a partir de los años 60. Observamos, además, que el descenso fue leve pero constante para todo el periodo 1980-2000. En 2010, por ejemplo, Marruecos presentaba una TBN de 20 nacimientos por cada mil habitantes, mientras que en los ańos cincuenta superaba los 50 por cada mil habitantes, reduciéndose esta TBN por tanto a más de la mitad. No obstante, es reseñable que esta TBN casi duplica la que en la actualidad presenta España. 


\section{Figura 2. Evolución del İndice Sintético de Fecundidad (ISF) 1950-2010}

Hijos por mujer

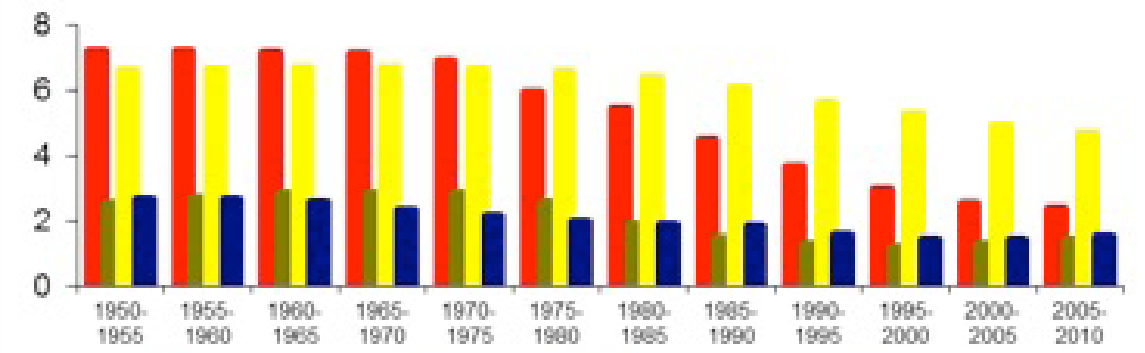

Fuentes: World Population Prospects (2010).

Elaboración: I. Macías, 2014. Haut Commissariat au Plan (Marruecos)

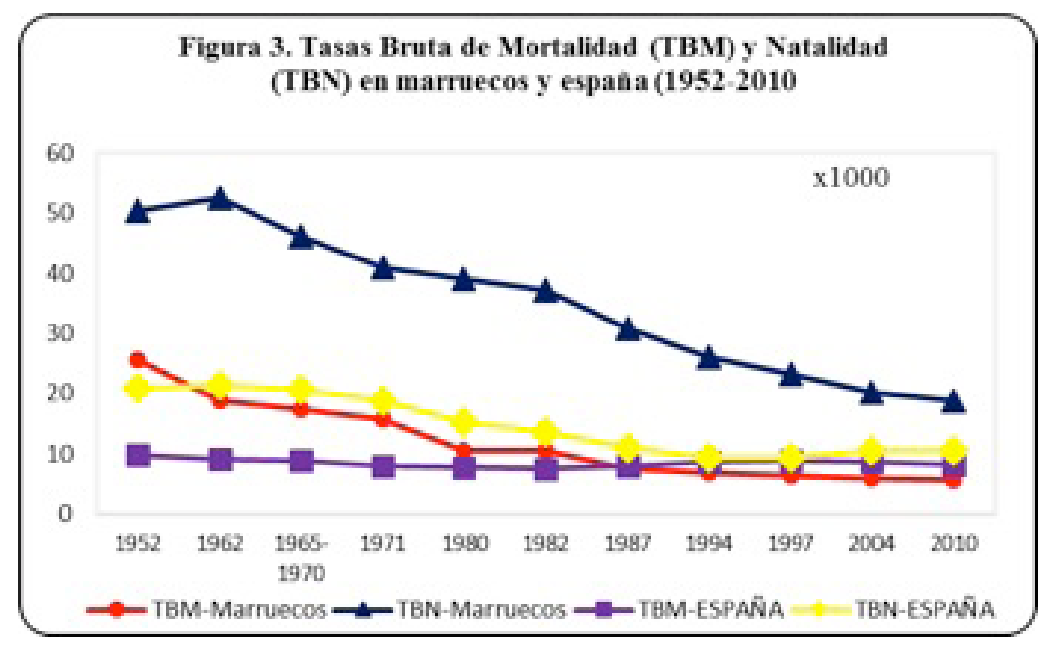

Fuente: Haut Commissariat au Plan (Marruecos) e INE (España).

Elaboración: I. Macías, 2014

Sin embargo, las condiciones de salud de un país como Marruecos no son del todo apreciables sin considerar el indicador de la mortalidad infantil. Si bien es verdad que la tasa de mortalidad infantil (TMI) de Marruecos ha ido decreciendo de forma continua entre 1950 y 2010, pasando de unas 150 defunciones a 32,2 por cada mil nacimientos, sigue estando muy lejos de alcanzar las cifras espańolas o europeas (Figura 4). Es notable su decrecimiento respecto a la mortalidad infantil 
africana en general, pues aunque en 1962 corría muy cerca de las cifras para el continente africano en su conjunto, en la actualidad la TMI marroquí es más de dos veces menor que la africana (y más baja, también, que en cualquier otro país del norte de África). Con todo, la gravedad de este asunto queda reflejada en el siguiente cálculo: los niveles de mortalidad infantil en Marruecos en el periodo 1962-2010 equivalen a la mortalidad infantil de Espańa y de Europa en su conjunto en torno al año 1960. Por otra parte, las cifras relativas a la mortalidad de los niños menores de 5 años indican que en los últimos años (hasta el 2005), siguen falleciendo 46 nińos de esta edad por cada mil nacimientos en Marruecos, mientras que sólo se registran unas 6 muertes por mil nacimientos en España y unas 10 en el conjunto de los países más desarrollados ${ }^{4}$.

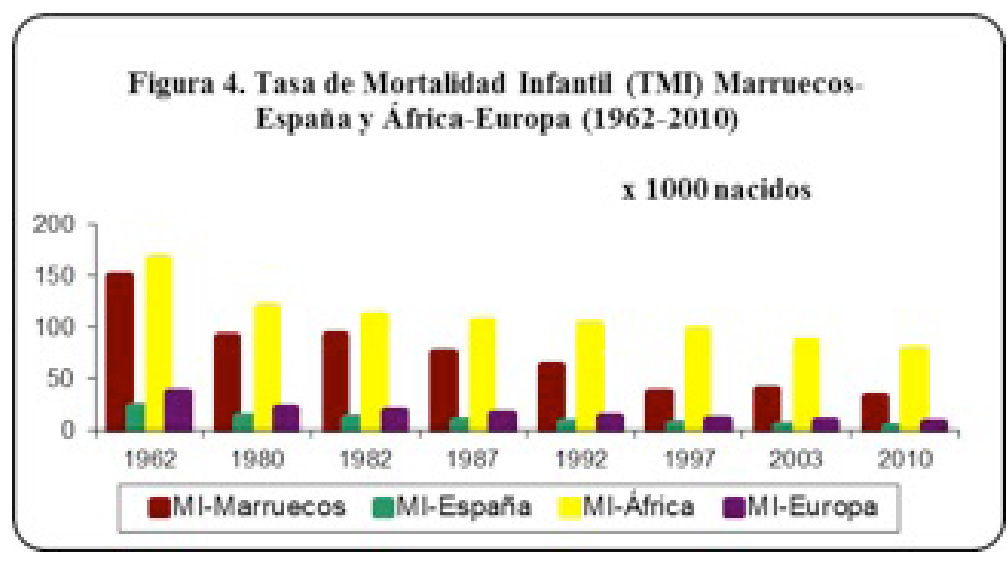

Fuente: Haut Commissariat au Plan (Marruecos), World Population Prospects 2010 e INE (España).

Elaboración: I. Macías, 2014

A pesar de este claro descenso en la TBN, los niños marroquíes que nacieron en plena explosión del fenómeno del "baby boom" están hoy en edad de trabajar y, como se demostrará más adelante, a la estructura del mercado de trabajo marroquí le es prácticamente imposible darles una salida laboral oficial. A muchas de estas personas le quedarán pocas alternativas: trabajo informal e ilegal, carestías o emigración. No es inverosímil sostener que la estabilidad poblacional de Marruecos, tras el "baby boom” de los años 60, no tendrá lugar — si lo tieneal menos hasta el año 2020, fecha donde presumiblemente se podrá entrever un inicial envejecimiento de la población actual.

4 Elisa Brey, "La transición demográfica en Marruecos", Documentos de trabajo, Vol. III, no 2 (2009), pp. 1-27. 
Si estudiamos la evolución de la población potencialmente activa (PPA) marroquí (entre 15 y 65 años) $)^{5}$ desde 1960 hasta nuestros días, comparándola con la población total (Figura 5), observamos cómo a partir de los años 70 la distancia entre la población potencialmente activa y la población total va incrementándose progresivamente:

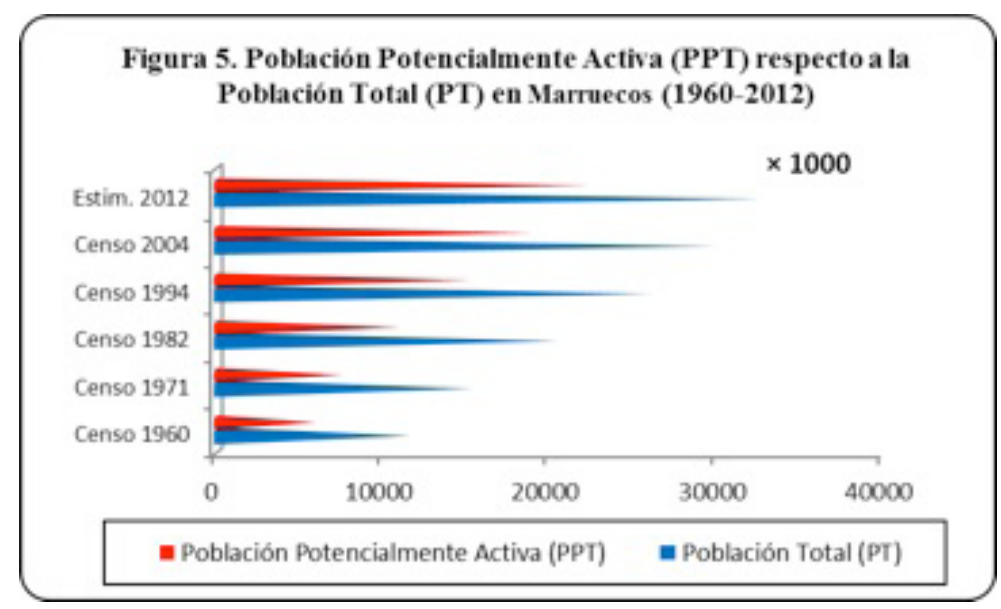

Fuente: Haut Commissariat au Plan (Marruecos).

Elaboración: I. Macías, 2014

Hay que subrayar, por último, que Marruecos alcanzó la tasa más alta de población potencialmente activa en la década 2000-2010, pero que el máximo global sólo se conseguirá en 2035 aproximadamente ${ }^{6}$. No obstante, estos datos

5 Como señalábamos en la introducción, el HCP no establece límite de longevidad alguno para el cálculo de la tasa de actividad (TA), puesto que se calcula simplemente con el volumen de personas de 15 años o más. Justo por ello, no encontramos, por ejemplo, ninguna estadística que refleje la población potencialmente activa (PPA), es decir, lo que en geografía entendemos por el volumen de personas en edad de trabajar (15-65 años). En cuanto al concepto de población activa (PA), el HCP también es ambiguo, sobre todo si lo comparamos con el Instituto Nacional de Estadística (INE) de España, ya que define a la persona activa del siguiente modo: "Una persona activa es una persona que pertenece a la mano de obra disponible para la producción de bienes y servicios, la realización de un trabajo productivo en una rama de la actividad económica o en busca de un trabajo" (definición extraída y traducida por nosotros de la siguiente web: http:// www.wmaker.net/myhcp2011/glossary/Personne-active gw8.html). Obsérvese, por tanto, que este concepto que nos ofrece el HCP no hace referencia alguna a la franja de edad estimable para el cómputo del parámetro. En consecuencia, para la elaboración de la Figura 5, hemos extraído las cifras relativas a la población potencialmente activa (PPA) partiendo de las estadísticas del HPC sobre la población total y dividida por edades respecto a la población total.

6 Samir Aita (Coord.), Empleo y derecho del trabajo en los paises árabes mediterráneos y el partenariado euromediterráneo. Madrid: Ed. de Fundación Paz y Solidaridad Serafín Aliaga de 
que reseñamos aquí adquirirán más sentido con los parámetros que analizaremos a continuación.

\subsection{Población activa ${ }^{7}$}

En el caso de Marruecos, la evolución de la población ocupada (PO) muestra en la última década una clara tendencia al estancamiento, prácticamente fijada en el umbral de los 10 millones. Sin embargo, el número de personas activas (PA), levemente por debajo de los 20 millones en 2001 (Figura 6a), ya los superaba en 2008, según los datos recogidos por la Oficina Internacional del Trabajo (OIT). La problemática inherente a estos datos se explicita aún más cuando los comparamos con otros países europeos afectados o no por la crisis internacional de 2007, como por ejemplo España ${ }^{8}$. La tasa de actividad (TA) española doblaba prácticamente a la marroquí en 2002, aunque es reseńable su descenso a partir del 2006, pasando de un $90 \%$ a un $75 \%$, debido a las consecuencias inherentes a la crisis internacional (Figura 6b).

No obstante, es necesario seńalar que los parámetros referidos a Marruecos recogidos en la Figura 6a acopian los datos recogidos por las encuestas sobre la fuerza de trabajo realizadas por el departamento de estadística de la Organización Internacional del Trabajo (OIT), publicadas en 2008. Hemos optado por esta fuente de información estadística porque tales encuestas tienen en cuenta también la explotación infantil, incluyendo en sus muestras aquellos jóvenes de más de 7 años que realizan alguna actividad considerada como laboral, algo que no es fácil de apreciar en la información estadística que ofrece el Haut Commissariat au Plan (HCP) de Marruecos.

Comisiones Obreras, 2008, p. 25.

7 La población activa de un país resulta de la cantidad de personas en edad de trabajar que forman parte del mercado de trabajo, es decir, que tienen un empleo o lo están buscando. Luego este parámetro se suele subdividir en dos: la población empleada (PE) y la población desempleada (PD). El cálculo de esta variable se realiza en función de la población comprendida entre los 15 y los 65 años, aunque el HCP de Marruecos parece que, aunque parte de los 15 ańos de edad para el cálculo, no impone sin embargo límite de longevidad al mismo (Véase nota 5).

8 España, Irlanda, Portugal, Grecia e Italia son los países de la Unión Europea que más han sufrido la crisis internacional del 2007. En España las cifras de paro son alarmantes, superando los 6 millones de parados y con una tasa de desempleo juvenil de más del 50\% en 2012, muy por encima de la media europea. 


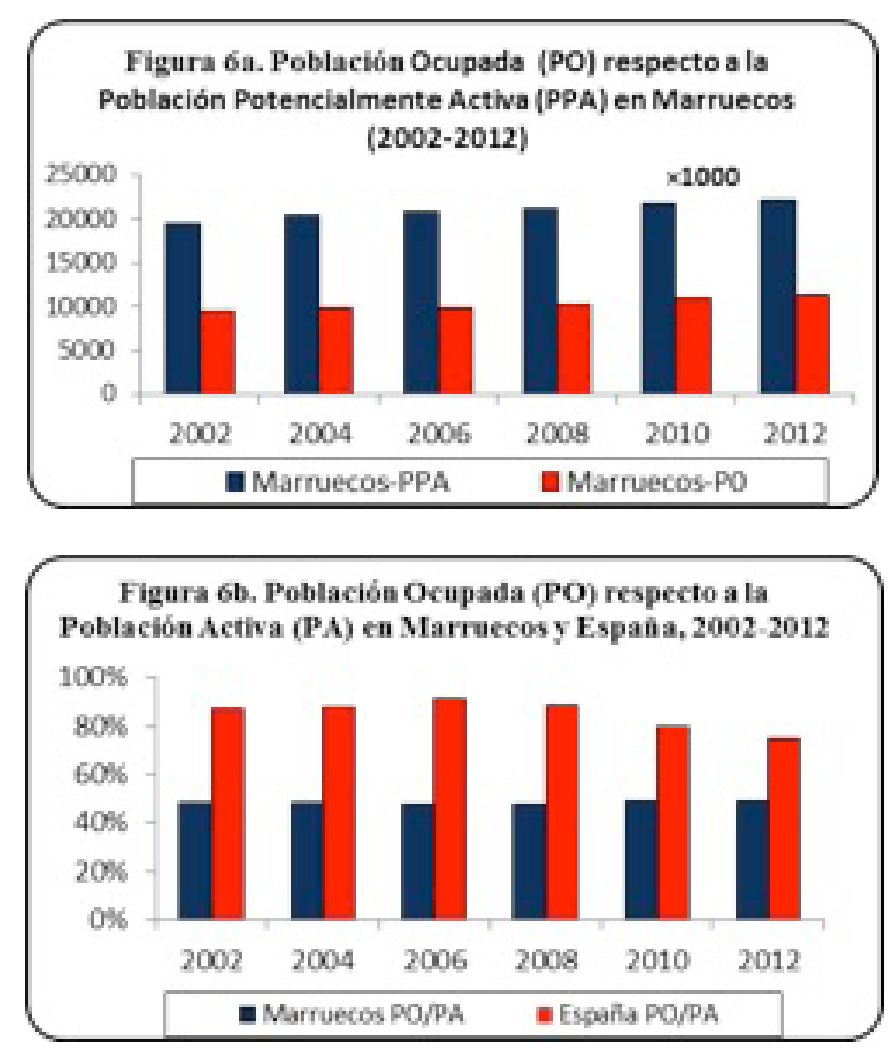

Fuentes: LABORSTA INTERNET (Dep. de estadística dela Oficina Internacional del Trabajo), Haut Commissariat au Plan (Marruecos) e INE (Espańa) Elaboración: I. Macías, 2014

Concretamente, la encuesta realizada por la OIT del 2004 resaltaba la importancia de este problema, citando una encuesta de la UCW (Understanding Children's Work) de 2003 que afirmaba que más de 600.000 nińos podrían encontrarse trabajando en Marruecos. Sin embargo, estas cifras podrían verse superadas por la realidad, ya que más de un millón de niños en edad de escolarización no asisten a la escuela9. En este sentido, mientras que los datos registrados sobre explotación infantil en la actualidad son nulos respecto al territorio español, en Marruecos se sigue encontrando un porcentaje bastante alarmante, aunque a veces muy difícil de ponderar $y$, sobre todo, de erradicarse por ley:

9 Samir Aita (Coord.), Empleo y derecho del trabajo..., p. 32. 
"El Alto Comisionado para el Plan, un organismo oficial, calcula que el año pasado aún trabajaban en Marruecos 147.000 niños menores de 15 años, es decir, el 3\% de los que están en esa franja de edad. La cifra solo representa un $28 \%$ de los que trabajaban diez años antes $(517.000$, el $9,7 \%)$. Para hacer esta estimación los encuestadores del Alto Comisionado visitaron 60.000 hogares repartidos por todo Marruecos. De los nińos que actualmente lo siguen en la vida laboral, entre 60.000 y 80.000 están empleados en el servicio doméstico, según ONG marroquíes de protección de la infancia. En su mayoría son niñas de áreas rurales que, a veces con tan solo siete años, ya sirven en las casas de la burguesía de las grandes ciudades. No suelen disfrutar de un descanso semanal y no son ellas las que cobran el pequeño estipendio sino sus padres" ${ }^{\prime \prime}$.

Por último, la evolución de la tasa de desempleo (TD $)^{11}$ en la última década se ha mantenido constante, en torno al 10\% (Figura 7), bajando un $4 \%$ desde 1999 a las cifras que se cotejan en 2011. Esta bajada de 4 puntos indica una leve mejoría para la situación actual del demandante de empleo marroquí ${ }^{12}$. No obstante, es necesario advertir que la mayoría del empleo se encuentra en el sector primario, en actividades vinculadas a la agricultura, donde los salarios y las condiciones materiales de existencia de los agricultores son lamentables, registrándose abismales disparidades territoriales de norte a sur que sitúan al conjunto de estas personas muy cerca de los umbrales de la supervivencia. De hecho, el HCP publicó en 2011 que la población activa ocupada en el sector primario rozó el $40 \%$ de la población activa en todo el territorio nacional, como veremos más adelante.

10 Ignacio Cembrero, "Marruecos quiere erradicar el trabajo infantil", El País. Puesto en línea el 17/10/2011. Disponible en http://elpais.com/diario/2011/10/17/sociedad/1318802402 850215 . html. Consultado el 29/10/2014.

11 El departamento de estadística del HCP expresa en el cálculo de la tasa de desempleo (TD) el porcentaje de desempleados de 15 ańos y más. Esta tasa se obtiene calculando la relación entre el número de parados y de trabajadores mayores de 15 años. De nuevo aquí no se impone ningún límite de longevidad para el cálculo de esta tasa (Véase de nuevo nota 5).

12 Es importante señalar que en Marruecos no existe un sistema de prestación al desempleo parecido al que existe en los distintos países de la Unión Europea. Justo por ello, la cifras de paro que se no ofrecen no se ajustan totalmente a la realidad, pues muchos de los demandantes de empleo, sobre todo en las zonas rurales, ni siquiera se declaran oficialmente como tales. Si lo hicieran, seguramente las cifras de paro aumentarían considerablemente. 
Figura 7. Tasa de Desempleo (TD) respecto a la Tasa de Actividad (TA) en Marruecos (1999-2011)

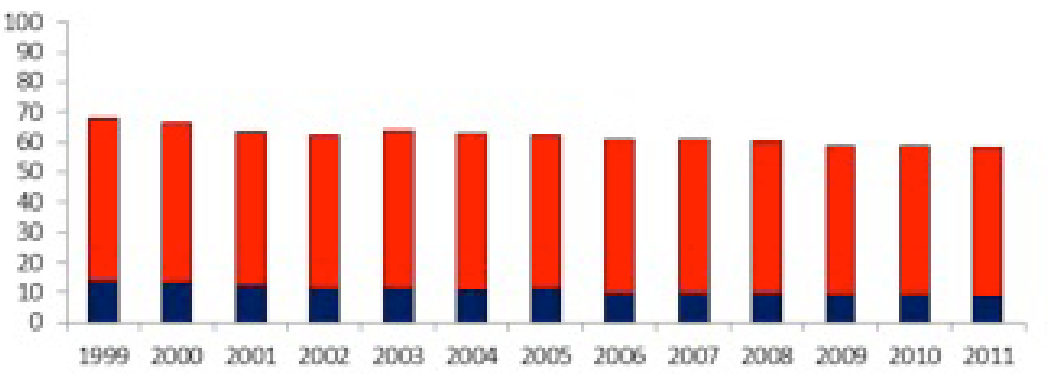

Tasa de actividad (TA)

Tasa de Desempleo (TD)

Fuente: Haut Commissariat au Plan (Marruecos).

Elaboración: I.Macías, 2014

2.3. Participación de la mujer marroquí en el mercado laboral

Además de erradicar la explotación infantil, otro de los grandes retos a superar por los países en vías de desarrollo es la incorporación de la mujer al mercado de trabajo. En los países árabes mediterráneos, debido principalmente a su cultura y política, así como a una más que escasa industrialización de sus territorios, la mujer se encuentra en una clara desventaja respecto al hombre a la hora de participar en la vida económica del país, a pesar de que cada ańo se registre un tímido avance.

En su inmensa mayoría, el futuro de las mujeres en países como Egipto, Túnez, Jordania, Líbano, Palestina, Siria o Marruecos se desarrolla desempeñando roles primitivos dentro de la familia y en las explotaciones agrícolas y artesanales. Y, aunque afortunadamente esta situación va cambiando, en la actualidad tales cambios no logran mejorar considerablemente la situación laboral del género femenino. No obstante, mientras que en 1950 el sector de las mujeres dentro de la población activa era de un 5\%, actualmente ha rebasado el $20 \%$ en todos los países árabes del mediterráneo, excepto en Palestina ${ }^{13}$.

En la Tabla 1 podemos apreciar la posición que ocupa la tasa de actividad (TA) de la mujer marroquí dentro del conjunto de estos países musulmanes mediterráneos, comparándola con la de España. La TA para la mujer española duplicó en 2010 a la marroquí y, aunque respecto a otros países musulmanes ocupa un lugar más aventajado, estas cifras no recogen su verdadero impacto 
económico. El caso es que la mujer marroquí desempeña un papel esencial para la economía familiar, tanto en lo relativo a las tareas domésticas como en las labores agrícolas de pequeńas explotaciones, donde el esfuerzo del género femenino se desvela muy superior al de su opuesto.

Con todo, la Tabla 1 también refleja la importancia y el peso que está ganando la mujer trabajadora en la economía de sus respectivos países, más aún si tenemos en cuenta que "en la primera mitad de este siglo todas las mujeres marroquíes eran esclavas o amas de casa, excepto una minoría empujadas por la pobreza al trabajo remunerado, que fue una prolongación del trabajo doméstico -en las casas de colonos franceses o españoles, o dentro de algunas fábricas u hospitales-"14 En general, son las mujeres más jóvenes las que logran incorporarse al mercado de trabajo más fácilmente, aunque desempeñando aún trabajos precarios, mal remunerados y con salarios no equitativos respecto al de los hombres.

\begin{tabular}{|c|c|c|c|}
\hline \multicolumn{4}{|c|}{ Tabla 1. Tasa de actividad femenina en distintos países musulmanes del medi- } \\
terráneo y en España (1990-2010) \\
\hline Espańa & $\mathbf{1 9 9 0}$ & $\mathbf{2 0 0 0}$ & $\mathbf{2 0 1 0}$ \\
\hline Libia & $\mathbf{3 4 \%}$ & $\mathbf{4 1 \%}$ & $\mathbf{5 2 \%}$ \\
\hline Marruecos & $18 \%$ & $27 \%$ & $30 \%$ \\
\hline Túnez & $\mathbf{2 6} \%$ & $\mathbf{2 9} \%$ & $\mathbf{2 6 \%}$ \\
\hline Egipto & $21 \%$ & $24 \%$ & $25 \%$ \\
\hline Líbano & $27 \%$ & $20 \%$ & $23 \%$ \\
\hline Argelia & $17 \%$ & $19 \%$ & $15 \%$ \\
\hline Jordania & $10 \%$ & $12 \%$ & $15 \%$ \\
\hline Siria & $9 \%$ & $13 \%$ & $13 \%$ \\
\hline
\end{tabular}

Fuente: World Bank

Elaboración: I. Macías, 2014

14 Leila Chafai, "Las mujeres sujeto de marginación en Marruecos", Anales de Historia Contemporánea, $\mathrm{n}^{\circ} 13$ (1998), p. 37. 
En 2011, según las estadísticas del Haut Commissariat au Plan, la mujer marroquí empleada sólo llega a representar el $25,5 \%$ de la fuerza de la población total, mientras que el varón marroquí empleado acapara el 74,3\%. Además es imperceptible algún movimiento del volumen de mujeres que participa en la economía marroquí en toda la pasada década, si bien es verdad que tampoco encontramos ningún incremento significativo respecto a los hombres (Figura 8). Ante esta difícil situación laboral, hombres y mujeres marroquíes se han visto forzados a tener que emigrar ${ }^{15}$ a otros países, en la mayoría de los casos europeos, buscando una mejora de sus condiciones sociolaborales.

Insistir en que los sectores productivos marroquíes que contratan más mano de obra femenina son, sobre todo, el sector de la agricultura y la industria agroalimentaria, luego el sector textil y, por último, el sector servicios (doméstico, turístico o administrativo). En cuanto al sector público, las mujeres sólo representaban a finales de la década de los 90 un 1/5 de los funcionarios del Estado, aunque la mayoría de funcionarias marroquíes desempeñan funciones de baja escala ${ }^{16}$, cifra que se ha mantenido constante en el nuevo milenio.

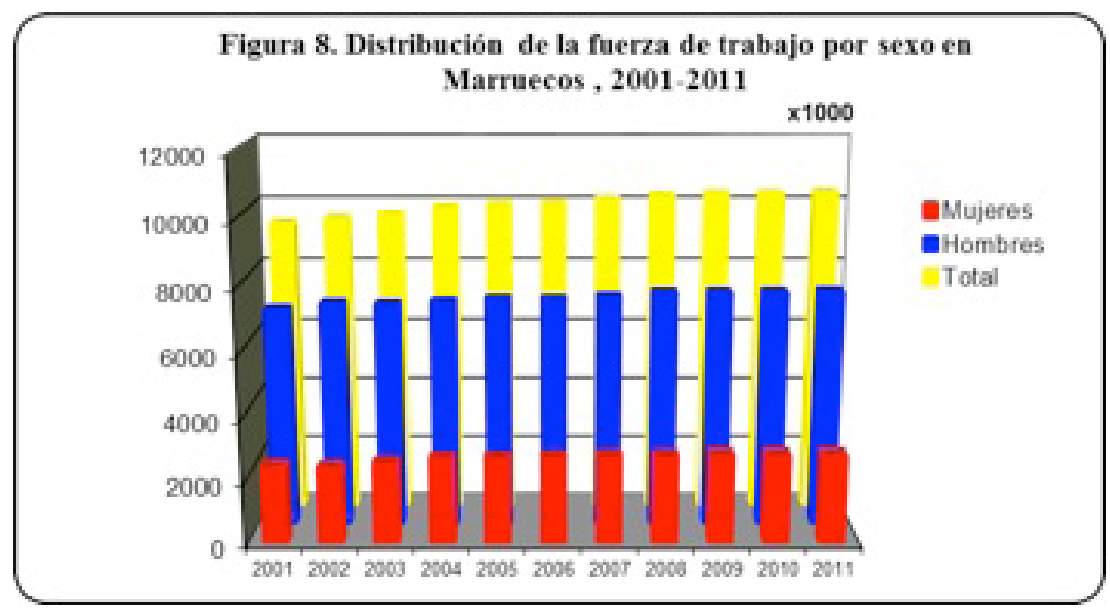

Fuente: Enquête nationale sur l'emploi, Haut Commissariat au Plan (Direction de la Statistique).

Elaboración: I. Macías, 2014

15 No obstante, el mayor volumen en los flujos emigratorios en Marruecos acontece en los años 80 y el destino mayoritario fue Francia.

16 Leila Chafai, Las mujeres sujeto de..., pp. 37-38. 
Por último, es importante reseñar que el índice de desigualdad de género (IDG) ${ }^{17}$ en Marruecos para el 2013 se sitúa en el $0.444 \%$ frente al $0.103 \%$ de España (Tabla 2), según los datos publicados por la Organización de Naciones Unidas (ONU). En términos generales, esta cifra señala que la desigualdad que la mujer marroquí padece en cada uno de los parámetros que se requieren para el cálculo de este índice - observables en la misma tabla — casi duplica a la del hombre marroquí. En este índice, por tanto, se subsume y cuantifica lo que parcialmente hemos venido sugiriendo a lo largo de todo este análisis, es decir que la raíz de la precariedad sociolaboral que se manifiesta para el caso de la mujer en marruecos es causada por una sociedad y cultura machista en gran parte de sus estamentos sociales.

Tabla 2. Índice de desigualdad de género Marruecos-España, 2013

\begin{tabular}{|l|c|c|}
\hline Indicadores: & Marruecos & Espańa \\
\hline $\begin{array}{l}\text { Población con al menos educación secundaria completa, } \\
\text { relación mujer/hombre (Relación tasa de mujeres-tasa de } \\
\text { hombres) }\end{array}$ & 0.553 & 0.937 \\
\hline $\begin{array}{l}\text { Tasa de fecundidad entre adolescentes (mujeres de entre } \\
15 \text { y } 19 \text { ańos) (la cantidad de partos por cada 1.000 } \\
\text { mujeres entre 15 y 19 ańos) }\end{array}$ & 15.1 & 12.7 \\
\hline $\begin{array}{l}\text { Tasa de participación en la fuerza de trabajo (Relación tasa } \\
\text { de mujeres-tasa de hombres) }\end{array}$ & 0.351 & 0.766 \\
\hline $\begin{array}{l}\text { Proporción en escańos en el parlamento: relación mujer/ } \\
\text { hombre. }\end{array}$ & 0.123 & 0.536 \\
\hline $\begin{array}{l}\text { Tasa de mortalidad maternal (muertes maternas por cada } \\
100.000 \text { nacidos vivos) }\end{array}$ & 100 & 6 \\
\hline Índice de Desigualdad de Género & $\mathbf{0 . 4 4 4}$ & $\mathbf{0 . 1 0 3}$ \\
\hline
\end{tabular}

Fuente: ONU, Índices de Desarrollo Humano: http://hdr.undp.org/es/ estadisticas/idg/

Elaboración: I. Macías, 2014

17 El Índice de Desigualdad de Género (IDG) refleja la desventaja de las mujeres en tres dimensiones, a saber salud reproductiva, empoderamiento y mercado laboral, para tantos países como datos de calidad razonable se dispongan. El índice muestra la pérdida de desarrollo humano causada por la desigualdad existente entre los logros de mujeres y varones en estas dimensiones. Varía entre el 0 , que indica que mujeres y varones presentan un desarrollo igual, y el 1, que supone que las mujeres registran el peor desarrollo posible en todas las dimensiones medidas (ONU, 2014). Para una mayor información sobre la metodología empleada para el cálculo de este parámetro remitimos al lector a la misma página Web de la ONU, desde la cual hemos extraído el concepto del mismo citado anteriormente: http://hdr.undp.org/es/estadisticas/idg/ 


\subsection{Fuerza de trabajo y formación educativa}

Es importante analizar brevemente la relación que existe entre la fuerza de trabajo y el nivel de formación de la población, puesto que revelarán importantes aspectos sobre la adaptación entre la oferta y la demanda de trabajo. Se ha convertido en axiomática, para cualquier investigación en esta área, la idea de que a mayor cualificación y formación profesional mejores oportunidades en el mercado de trabajo, aunque puedan observarse algunas excepciones. Si observamos de nuevo la tabla anterior es fácil comprender este axioma. En este sentido, la tasa de alfabetización (TA) en el mundo (Mapa 1) sitúa en 2010 a las personas marroquíes que "saben leer y escribir una sentencia sobre su vida diaria" en una posición muy alejada del grupo de países industrializados, entre el 50 y 69 $\%$ de la población total.

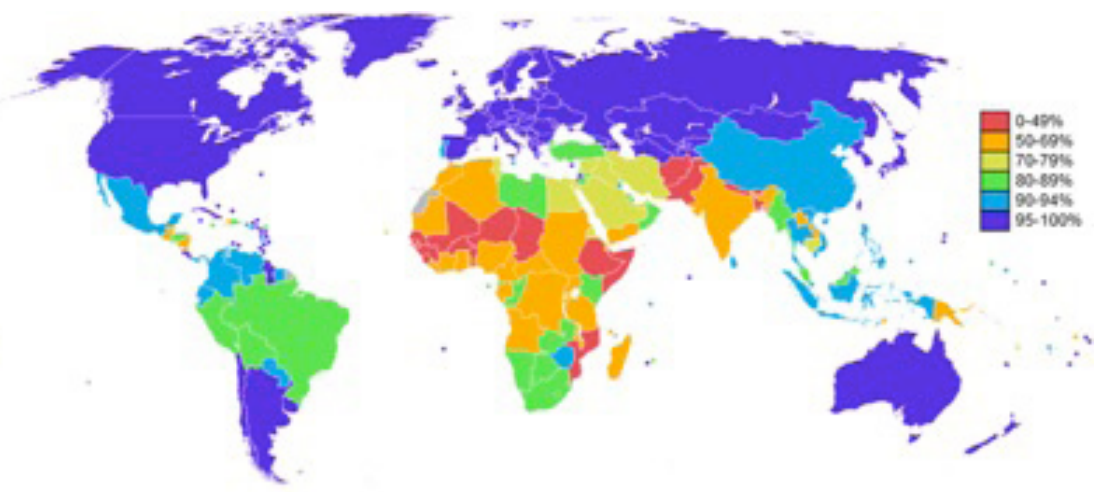

Mapa 1. Alfabetización en el mundo (2010) (\%)

Fuente: UN Development Report, 2010;

Elaboración: I. Macías (a partir de la aplicación de la web del UN Development Report: http://hdr.undp.org/es/estadisticas/)

El coeficiente neto de inscripción escolar (CNIE) para el nivel primario de estudios en Marruecos fue del $90 \%$ en 2009, de los que sólo un 13\% llegó a cursar el nivel terciario del CINE, según los últimos datos publicados por el World Bank ${ }^{18}$ (WB). Si, por otro lado, comparamos la tasa de analfabetismo entre hombres y mujeres jóvenes (15-24 años) de Marruecos con la del conjunto de países árabes del mediterráneo (Tabla 3), comprobaremos que Marruecos y

18 Nos vemos obligados aquí a utilizar esta fuente, ya que el Haut Commissariat au Plan (HCP) de Marruecos sólo nos ofrece la estadística sobre la tasa de analfabetismo referida al año 2004, teniendo en cuenta a las personas mayores de 10 ańos. 
Egipto ocupan las posiciones menos favorables en el ranking, muy alejado del 0\% de Libia y España, lo cual entrevé el horizonte laboral que comprenderá a estas personas y que estudiaremos más adelante. También van a la cabeza los universitarios jordanos y libios en empleabilidad, mientras que los egipcios y marroquíes vuelven a situarse en la cola (World Bank, 2008).

\begin{tabular}{|l|c|c|c|}
\hline \multicolumn{4}{|c|}{$\begin{array}{c}\text { Tabla 3. Tasa de analfabetismo joven (15-24 años) en distintos países } \\
\text { musulmanes del mediterráneo y España }\end{array}$} \\
\hline & Hombres & Mujeres & Año \\
\hline Marruecos & $\mathbf{2 4 \%}$ & $\mathbf{1 5 \%}$ & $\mathbf{2 0 0 4}$ \\
\hline Egipto & $11 \%$ & $16 \%$ & 2010 \\
\hline Argelia & $6 \%$ & $11 \%$ & 2006 \\
\hline Siria & $4 \%$ & 6 & 2010 \\
\hline Túnez & $2 \%$ & $4 \%$ & 2008 \\
\hline Líbano & $2 \%$ & $1 \%$ & 2007 \\
\hline Jordania & $1 \%$ & $1 \%$ & 2007 \\
\hline Libia & $0 \%$ & $0 \%$ & 2010 \\
\hline Espańa & $\mathbf{0 \%}$ & $\mathbf{0} \%$ & $\mathbf{2 0 1 0}$ \\
\hline
\end{tabular}

Fuente: World Bank (WB)

Elaboración: I. Macías, 2011

Ya en 1995 el World Bank elaboró la Carta Nacional de Educación y Formación para Marruecos, donde se identificó a la educación como uno de los ámbitos donde el gobierno marroquí debía actuar y reformar para situarse en una buena posición en los mercados internacionales y afrontar, de este modo, los desafíos del siglo XXI. Entre otras muchas cosas, la Carta planteó una serie de medidas contra el analfabetismo, pretendiendo reducir su tasa a menos del $20 \%$ en el ańo 2010, para que pudiera ser erradicado en el 2015. Se apela, en consecuencia, a una reforma que potencie la "educación no formal" dirigida, fundamentalmente, a jóvenes no escolarizados o que han abandonado la escuela ${ }^{19}$. En general, estos resultados no se han conseguido aún, constatándose por el contrario una

19 Laura Mijares Molina y Bernabé López García, “Sociedad y educación en Marruecos”, en Bernabé López García y Mohammed Berriane (Dir.): Atlas de la inmigración marroquí en España. Madrid: UAM-Observatorio Permanente de la Inmigración, 2004, pp. 50-52. 
tendencia clara al abandono prematuro en el sistema educativo en estos últimos años, teniendo en cuenta el empeoramiento de las condiciones económicas de la población en su conjunto ${ }^{20}$.

Como ya adelantábamos al principio, la formación educativa facilita a las personas su inserción en el mercado laboral, otorgándoles además mayor probabilidad de encontrar un trabajo acorde con su cualificación profesional y nivel académico alcanzado. En Marruecos la mayoría de los jóvenes de entre 15 y 24 años son analfabetos o que abandonaron pronto el sistema educativo desempeñan, cuando consiguen empleo, los trabajos peores remunerados y cualificados, ligados al sector primario (sobre todo a la agricultura). También ocurre lo mismo con aquellos que lograron cerrar el ciclo de estudios primarios, aunque en menor proporción.

Sin embargo, la esperanza de encontrar un empleo que permita alguna mejora socioeconómica sólo la experimentan aquellos marroquíes que logran superar la educación secundaria y terminar algún nivel de la educación superior. Aunque es necesario subrayar que en muchas ocasiones ese mejoramiento socioeconómico no se alcanza ni siquiera en otros países donde estos universitarios emigraron ${ }^{21}$. De todas formas, la evolución del analfabetismo en Marruecos (Figura 9), aún descendiendo tímidamente desde 1982, deja tras de sí pocas esperanzas para encontrar un trabajo remunerado a estas personas.

Figura 9. Evolución de la Analfabetización en Marruecos

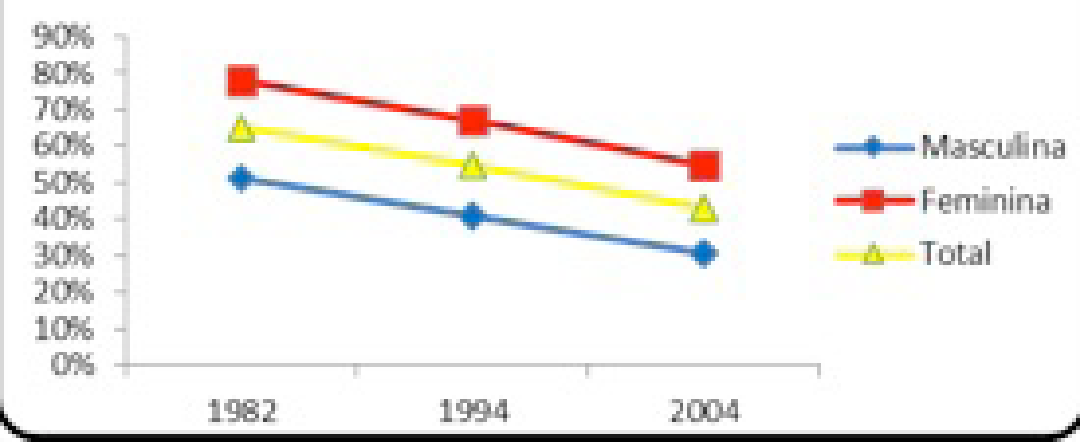

Fuente: Haut Commissariat au Plan

Elaboración: I. Macías, 2013 


\section{INDICADORES GENERALES DEL MERCADO DE TRABAJO}

\subsection{El empleo informal en el territorio de Marruecos}

A la hora de abordar las características generales del trabajo en Marruecos hay que tener presente la existencia de actividades laborales que participan de la así llamada "economía informal". Se trata, en concreto, del Trabajo Informal en Relación de Dependencia (TIRD), también llamado trabajo no registrado, trabajo en negro o trabajo sin contrato, el cual llega a constituir entre la mitad y las tres cuartas partes del empleo no agrícola en los países en desarrollo ${ }^{22}$. Este fenómeno económico ni es nuevo ni es propio de territorios económicos desfavorecidos, pues también en los países desarrollados se está multiplicando el trabajo informal en la actualidad. Se caracteriza principalmente por constituirse en una relación laboral sin cumplir las formalidades legales. Su estudio, comenzando por su cuantificación, es una ardua tarea para los investigadores.

El empleo informal se compone al mismo tiempo del empleo por cuenta propia en una empresa informal (generalmente pequeña y que no está registrada) y del empleo asalariado no declarado formalmente (sin contrato de trabajo y protección social, en empresas formales o no, a domicilio o sin empleados fijos). El primer subtipo se da con mayor frecuencia en países en vías de desarrollo, mientras que el segundo se desarrolla normalmente en los países industrializados, aunque también es muy probable que podamos encontrarlos juntos en la vida económica de cualquier territorio al margen del grado de desarrollo alcanzado. Son las mujeres el segmento de población más afectado por el empleo informal, representando el 43\% del total de las mujeres empleadas en los países del Magreb, fuera de la agricultura ${ }^{23}$.

En Marruecos se disparan las cifras de empleados informales, pues abarca cerca del $50 \%$ de los empleos ${ }^{24}$. El último Informe sobre Desarrollo Humano en Marruecos, realizado por la Oficina del Informe sobre Desarrollo Humano (OIDH) en 2006, revela que el empleo informal en este país alcanza el $40 \%$ del empleo total no agrícola, dominando el sector urbano (72\% de las unidades de producción). Señala, por otro lado, que las causas principales que lo generan se deben al éxodo rural, al deterioro del mercado de trabajo asalariado y al aumento de la precariedad, la pobreza y los errores en el sistema educativo. El Profil Pays Maroc $^{25}$ de 2004 realizado por el Institut de las Mèditerranée subraya, por su parte,

22Hamid Zidouni, "Evaluation et analyse de la place le l'economie Informelle en Algérie: approche de la comptabilité nationale", Séminaire sur l'économie informelle et la fiscalité. Algeria: Forum des chefs d'entreprises, 2003.

23 Samir Aita (Coord.), Empleo y derecho del trabajo..., p. 65.

24 Jean Paul Barbier Barbier, Lintermédiation sur le Marché du Travail dans les Pays du Maghreb; Etude Comparative entre l'Algérie, le Maroc et la Tunisie. Genova: Bureau International du Travail, 2006.

25 Se trata de un estudio exhaustivo del mercado de trabajo en Marruecos, coordinado por 
que el empleo informal en Marruecos afecta más a los hombres, concretamente al $72 \%$ de los empleados activos en el medio urbano, y solamente al $27 \%$ en el medio rural. También afirma que el sector informal no agrícola supone el 17\% del PIB nacional.

\subsection{Distribución del empleo entre los principales sectores económicos:}

En general, los países musulmanes del mediterráneo se mantienen dentro de una economía primaria, donde el empleo agrario sigue representando un peso determinante para los trabajadores. El departamento de estadística del HCP ofrece estadísticas sobre la distribución del empleo en sectores económicos, separando el porcentaje de población activa ocupada que se registra en el medio rural del que se coteja en el urbano ${ }^{26}$ (Tabla 4). De hecho, en Marruecos en 2011 casi un $75 \%$ de la población empleada en el sector primario se localiza en el medio rural. Es más, dentro del conjunto de países árabes del Mediterráneo, Marruecos representa el territorio que más empleados presenta en actividades agrícolas, con un $40,9 \%$ de empleo respecto al número total de empleos, muy por encima de Egipto o Argelia (Tabla 5).

\begin{tabular}{|c|c|c|c|c|c|c|}
\hline \multicolumn{7}{|c|}{$\begin{array}{l}\text { Tabla 4. Distribución del empleo en sectores económicos en Marruecos } \\
\qquad 2000-2011\end{array}$} \\
\hline \multirow[t]{2}{*}{ Años } & \multicolumn{2}{|c|}{$\begin{array}{l}\text { Sector Primario } \\
\text { (1) }\end{array}$} & \multicolumn{2}{|c|}{ Sector Secundario (2) } & \multicolumn{2}{|c|}{ Sector terciario (3) } \\
\hline & $\begin{array}{c}\text { Rural } \\
(\%)\end{array}$ & $\begin{array}{l}\text { Urbano } \\
(\%)\end{array}$ & $\begin{array}{c}\text { Rural } \\
(\%)\end{array}$ & $\begin{array}{l}\text { Urbano } \\
(\%)\end{array}$ & $\begin{array}{c}\text { Rural } \\
(\%)\end{array}$ & $\begin{array}{l}\text { Urbano } \\
(\%)\end{array}$ \\
\hline 2000 & 80,9 & 5,1 & 8,5 & 31,9 & 10,5 & 62,8 \\
\hline 2002 & 80,4 & 4,9 & 8,8 & 32,3 & 10,7 & 62,7 \\
\hline 2004 & 79,7 & 5,4 & 9,2 & 31,8 & 11,0 & 62,8 \\
\hline
\end{tabular}

FEMISE (Forum Euroméditerranéen des Instituts de Sciences Économiques), realizado por Institut de las Mèditerranée y financiado por la UE. Desplegable en: http://www.femise.org/PDF/cp/cpmaroc-0407.pdf

26 Compruébese esta peculiaridad estadística en el siguiente enlace: http://www.hcp.ma/ Emploi-par-branche-d-activite-de-la-population-active-occupee-au-milieu-rural_a154.html. No obstante, no se nos explica en ningún momento qué se entiende por medio rural y medio urbano, así como tampoco qué se entiende por personas activas y ocupadas en el medio rural o urbano. Por tanto, no sabemos exactamente si estas personas sólo trabajan o trabajan y viven en los distintos sectores económicos localizados en el medio rural o urbano. Particularmente nos inclinamos por lo segundo. 


\begin{tabular}{|l|c|c|c|c|c|c|}
\hline $\mathbf{2 0 0 6}$ & 77,8 & 5,3 & 10,2 & 31,5 & 12,0 & 63,1 \\
\hline $\mathbf{2 0 0 8}$ & 75,2 & 5,5 & 11,7 & 32,0 & 12,9 & 62,3 \\
\hline $\mathbf{2 0 1 0}$ & 75,2 & 4,8 & 11,8 & 32,4 & 12,9 & 62,5 \\
\hline $\mathbf{2 0 1 1}$ & 74,9 & 4,9 & 11,6 & 32,0 & 13,5 & 62,9 \\
\hline
\end{tabular}

Fuente: Haut Commissariat au Plan (Marruecos)

Elaboración: I. Macías, 2013

Tabla 5. Empleos en agricultura en los países árabes del mediterráneo (\% del total del empleo)

\begin{tabular}{|l|c|c|}
\hline & AGRICULTURA & AÑO \\
\hline Marruecos & $\mathbf{4 0 , 9} \%$ & $\mathbf{2 0 0 8}$ \\
\hline Egipto & $31,6 \%$ & 2008 \\
\hline Argelia & $20,7 \%$ & 2004 \\
\hline Siria & $17,1 \%$ & 2004 \\
\hline Túnez & $16,3 \%$ & 2004 \\
\hline Palestina & $16,0 \%$ & 2004 \\
\hline Líbano & $6,7 \%$ & 2004 \\
\hline Jordania & $3,0 \%$ & 2009 \\
\hline
\end{tabular}

Fuente: World Bank (WB) y Haut Commissariat au Plan (Marruecos) Elaboración: I. Macías, 2013

Destacar, por otro lado, que en muchos casos el empleo agrícola es prácticamente femenino. Es el caso de Marruecos, donde las mujeres que trabajan en actividades agrícolas representaban el 59\% del total en 2009, mientras que los hombres sólo alcanzaban el 15,6\%, según los datos registrados y publicados por 
el World Bank $^{27}$ en 2011. Las características del empleo que genera la agricultura marroquí bien pueden resumirse en dos palabras: precariedad socioeconómica.

En el sector secundario, el empleo se sitúa alrededor del 13 y el 15\% del empleo total en todos los países árabes del mediterráneo. En Marruecos los datos publicados por el World Bank en 2011 afirmaban que un 15\% de mujeres activas desempeñaron en 2008 alguna actividad registrada en este sector, frente al 24\% de los hombres. Sin embargo, el porcentaje de mujeres que trabajan en este sector es muy variable de un país a otro, ya que en Argelia, por ejemplo, el $42 \%$ de los empleados en este sector son mujeres, mientras que en Egipto sólo constituyen el 6,9\% (Tabla 6). Con todo, la mayoría de estos países árabes, después de haber vivido un periodo de crecimiento industrial tras su independencia, padecen actualmente una caída del empleo industrial muy significativa ${ }^{28}$.

\begin{tabular}{|l|c|c|c|}
\hline \multicolumn{4}{|c|}{$\begin{array}{c}\text { Tabla 6. Trabajadores (\%) } \\
\text { musulmanes del }\end{array}$ en el sector secundario en los países } \\
& HOMBRES & MUJERES & AÑO \\
\hline Marruecos & $\mathbf{2 4 \%}$ & $\mathbf{1 5 \%}$ & $\mathbf{2 0 0 8}$ \\
\hline Egipto & $27 \%$ & $6,9 \%$ & 2008 \\
\hline Argelia & $13,6 \%$ & $42 \%$ & 2004 \\
\hline Siria & $21 \%$ & $10 \%$ & 2004 \\
\hline Túnez & $33 \%$ & $46 \%$ & 2004 \\
\hline Palestina & -- & --- & --- \\
\hline Líbano & --- & --- & -- \\
\hline Jordania & $21 \%$ & $10 \%$ & 2009 \\
\hline
\end{tabular}

Fuente: World Bank (WB)

Elaboración: I. Macías, 2013

27 Nos ceñimos a esta fuente de información estadística en este aspecto porque el Haut Commissariat au Plan de Marruecos no ofrece cifra alguna respecto a la distribución por sexo en el trabajo agrícola. Es más, el volumen de personas que desempeñan su labor en actividades agrícolas queda subsumido al sector agropecuario en las estadísticas de este organismo oficial, junto con la pesca y la ganadería. Es necesario, por tanto, completar estas cifras con otras fuentes de información geográfica.

28 Samir Aita (Coord.), Empleo y derecho del trabajo..., p. 38. 
El sector turístico es también un importantísimo motor del empleo, que generó más de un millón de empleos en 2011, según los datos publicados por el Haut Commissariat au Plan de Marruecos. En la actualidad, el turismo representa uno de los principales motores de crecimiento de la economía marroquí, hasta el punto de suponer la segunda fuente de entrada de divisas del país ${ }^{29}$.

\subsection{Trabajo y emigración}

En un territorio dominado económicamente por el sector primario y, por tanto, donde la agricultura, la ganadería y la pesca dependen de las inclemencias del tiempo, el mercado de trabajo de trabajo se ve sometido a la inestabilidad y la temporalidad laboral. Efectivamente, los empleos que generan las actividades primarias marroquíes son, casi en su totalidad, empleos de temporada. Si a este aspecto se le suma la dureza del trabajo en el campo y en la mar, la precariedad laboral, salarios bajos, la poca regularización legislativa laboral por parte del estado marroquí, las pocas alternativas al sector primario, la dependencia de los cultivos respecto al comercio exterior, la pobreza, el analfabetismo, los problemas de corrupción, la falta de democracia en las instituciones, etc., es fácil entender cómo muchos marroquíes arriesgan sus vidas intentando atravesar en patera el estrecho de Gibraltar.

El éxodo rural hacia las urbes marroquíes y hacia los países de la Unión Europea son dos de las consecuencias socioeconómicas más sobresalientes que se dan en Marruecos desde prácticamente el inicio de la independencia del Protectorado hispano-francés (1912-1956). En la década de los años 60, la emigración hacia Europa vino determinada, en parte, por los propios requerimientos de ésta de la mano de obra marroquí, cifrándose el contingente en varias decenas de millares de obreros, que se incorporaron principalmente a la industria minera, pero que con el tiempo se emplearon en otros sectores ${ }^{30}$. Sin embargo, a consecuencia de la crisis que sufrió Europa en los años 70, la cual hizo aumentar rápidamente la tasa de paro, el conjunto de los países europeos cerraron sus puertas a la inmigración.

En este sentido, la firme decisión de los países europeos en 1974 por detener oficialmente la inmigración propició, por el contrario, la aparición de otras formas de emigración marroquí, como la reagrupación familiar, la emigración temporal y la emigración clandestina. Tanto es así que el volumen de marroquíes que efectivamente residen en el exterior se ha duplicado en las dos décadas pasadas,

29 Oficina Económica y Comercial de España en Rabat, Guía Pais. Marruecos 2010. Rabat: Secretaría de Estado de Comercio, 2010, p. 11.

30 Abderrahim Sassi, "Migración internacional marroquí: balance y perspectivas", en Carlos Gonzáles Gutiérrez (Coord.): Relaciones Estado-Diáspora: aproximaciones desde cuatro continentes, Tomo I. México: SRE-IME/Universidad Autónoma de Zacatecas/ANUIES/Miguel Ángel Porrúa, 2006, p. 138. 
pasando de los 1.662 .870 en 1988 a los 3.300 .000 emigrantes en 2006, fecha hasta donde llegan las estadísticas oficiales de Marruecos ${ }^{31}$.

Francia, líder europeo en inmigración marroquí, presentaba en 2005 la cifra de 1.036.909 inmigrantes marroquíes, es decir, el 36\% de los marroquíes residentes en Europa. Le seguía España (destino preferido por los emigrantes marroquíes a partir de 1980) con 503.171 inmigrantes en el mismo año, Bélgica con 354.161, Italia con 345.564 y Países bajos con 324.511 (Figura 10). En total, fueron más de 2,7 millones de inmigrantes marroquíes en Europa ${ }^{32}$ en (HCP, 2005).

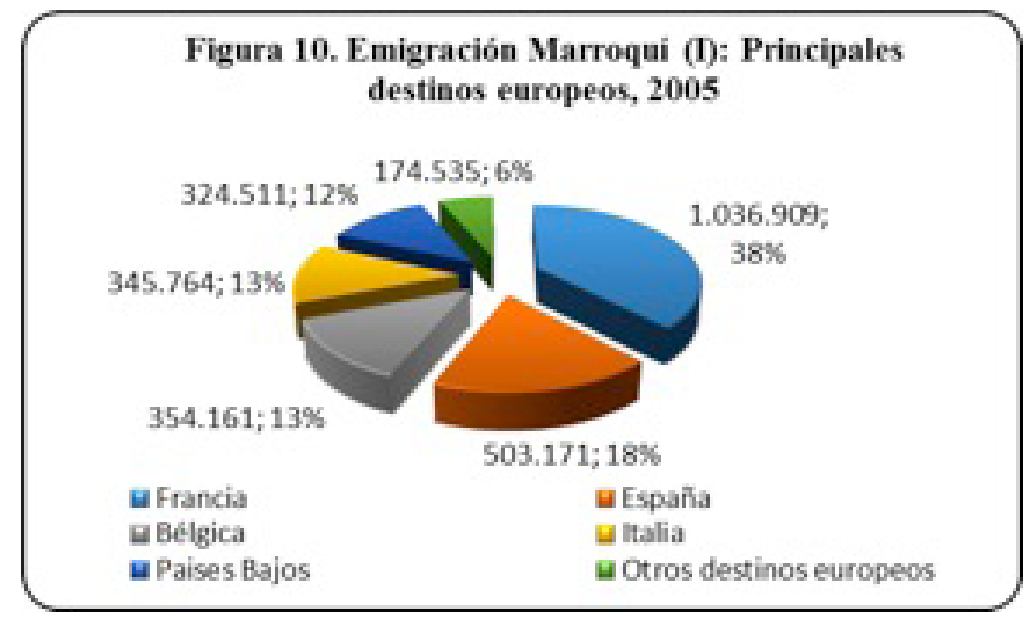

Fuente: Haut Commissariat au Plan (Marruecos). Elaboración: I.Macías, 2013

En la región árabe mediterránea se registró más de 200.000 inmigrantes de procedencia marroquí (HCP, 2005). Entre los destinos preferidos por

31 El Haut Commissariat au Plan no ofrece datos más actualizados sobre los residentes marroquíes en el exterior. Los únicos datos publicados son del 2006, como se puede comprobar en el siguiente enlace: http://www.hcp.ma/Effectif-des-Marocains-residant-a-l-etranger-MRE_a705. html. Sin embargo, Naciones Unidas si nos ofrece estadísticas actuales de la emigración marroquí en 2013. Según esta fuente estadística, el número de emigrantes marroquíes en el mundo es de 1.606.783, lo que supone que este volumen ha decrecido hasta casi la mitad en tan sólo 7 ańos. Este aspecto no concuerda con el movimiento natural de las migraciones y, por tanto, es necesario subrayarlo aquí. Se pueden observar estos datos en el siguiente enlace: http://esa.un.org/ unmigration/TIMSO2013/migrantstocks2013.htm?msdo

32 Las cifras que presentamos aquí son del 2005, fecha hasta donde llegan las estadísticas oficiales de Marruecos. De nuevo como en el caso anterior, Naciones Unidas ofrece datos que llegan hasta el 2013, donde se puede apreciar un descenso considerable. Francia, por ejemplo, pasaría del millón de inmigrantes en 2005 según el HCP a un poco más de 700.000 inmigrantes en 2013, seguido de España con 134.656, reduciéndose por tanto a mucho más de la mitad. 
los emigrantes marroquíes (Figura 11), Libia ocupa el primer lugar ${ }^{33}$ con casi 80.000 inmigrantes, siguiéndole Argelia con 62.822 y Arabia Saudí rozando los 28.000, que aun no siendo mediterránea también representa uno de los destinos principales para los marroquíes que residen en el exterior.

\section{Figura 11. Emigración Marroqui (II): Principales} destinos a paises árabes, 2005

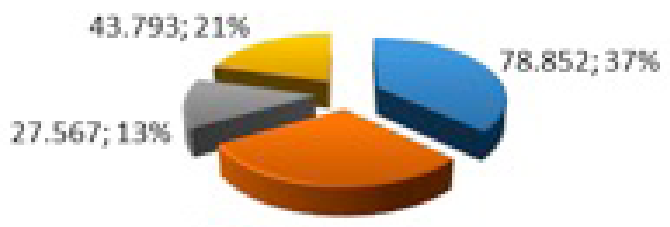

$62.822 ; 29 \%$

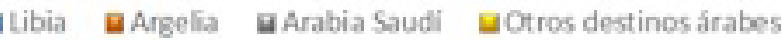

Fuente: Haut Commissariat au Plan (Marruecos).

Elaboración: I.Macías, 2013

En otros continentes también encontramos un número significativo de inmigrantes marroquíes. América, por ejemplo, presenta el mayor, con 226.196 inmigrantes (HCP, 2005), seguido de África y Asia-Oceanía (Figura 12), con un número mucho menor. De todas formas, el continente europeo sigue aupándose en la actualidad como el primer destino del emigrante marroquí, con el $86 \%$ de los inmigrantes marroquíes a escala mundial.

33 Aunque el HCP no nos ofrezca datos de migraciones más actuales, suponemos que la Primavera Árabe ha alterado considerablemente estas cifras en la actualidad, del mismo modo que a la tendencia del marroquí para emigrar hacia los países afectados por la misma. 


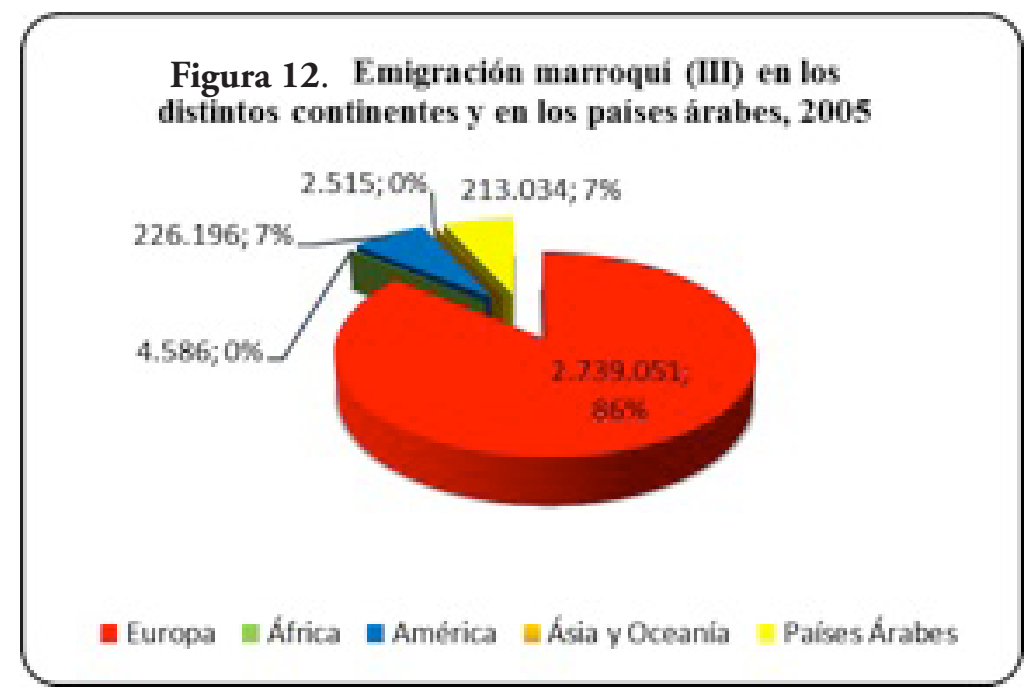

Fuente: Haut Commissariat au Plan (Marruecos).

Elaboración: I.Macías, 2013

\section{Conclusiones finales}

A juzgar por los datos que hemos ido analizando en este capítulo, al gobierno de Marruecos se le plantean numerosos retos que difícilmente puedan ser resueltos a corto plazo. Es prácticamente impensable la adopción de medidas políticoeconómicas eficientes que logren, en un breve lapso de tiempo, emplear a más del $50 \%$ de la población marroquí en edad de trabajar. Un ejemplo claro al respecto lo tenemos en España, que viene soportando una elevadísima tasa de paro desde el 2007, en la que todas las medidas e instrumentos adoptados en los 4 últimos años no han logrado mostrar ninguna mejora al respecto. Y, por otro lado, de pensarse en estas medidas, seguramente se desvelarían incompatibles con una cultura y una idiosincrasia poco o nada dada a cambios sustanciales que pudieran modificar su estructura social.

Tales medidas deberían haber sido adoptadas mucho tiempo atrás, con toda seguridad en el periodo anterior a la extraordinaria eclosión demográfica que el territorio sufrió entre los años 50 y 60 del pasado siglo. Efectivamente, sería fácil pensar en medidas apriorísticas que dinamizaran el sector industrial marroquí. Aunque tales medidas chocarían - como lo hacen en la actualidad - con las escalofriantes cifras de analfabetismo, por un lado, y la poca participación de la mujer marroquí en el tejido económico del país, por otro. Y, ciertamente, el dinamismo y fortaleza de todo sector industrial moderno se define fundamentalmente por una mano de obra cualificada e instruida (exceptuando el caso de países como China o India). La sangría de la emigración seguirá, por 
tanto, manifestándose como una de las "mejores" alternativas para el ciudadano marroquí con pocos recursos económicos, al menos durante los próximos años.

A largo plazo, la evolución demográfica de Marruecos abre un horizonte de esperanza para el 2020, fecha en la que aproximadamente se puede entrever el inicio de un envejecimiento de la población y el reemplazo de la población activa en esas edades por otras de tramos jóvenes. Mientras tanto, el gobierno marroquí deberá trabajar fuertemente por fortalecer un sistema que logre integrar a su población en los distintos sectores económicos, a través de una planificación estratégica del sistema educativo, con el fin de otorgar a la ciudadanía marroquí de una instrucción cualificada y ajustada al devenir de la era de la globalización. Para ello, Marruecos debería aprovechar el relativo éxito que viene mostrando el sector servicios en la última década e invertir, por tanto, parte de sus beneficios en una eficiente educación. De ahí, es decir, de una población instruida, podría venir un cambio generacional que implicara un nuevo rol para la mujer dentro de la cultura marroquí, un cambio en las estructuras de gobierno o incluso el paso hacia una democracia, entre otras muchas cosas.

La proximidad de Marruecos al continente europeo, sumado al extraordinario esfuerzo geopolítico y diplomático que ha desarrollado su gobierno a lo largo de las últimas dos décadas hacia la Unión Europea, le ha consagrado como "Socio Preferente" de esta última, según se desprende del Estatuto Avanzado concedido en 2008 por la UE a Marruecos. La UE, por tanto, viene ofreciendo a Marruecos desde esta fecha un trato especial respecto a los demás países no-comunitarios con los que mantiene relaciones político-económicas. Pero también deberes, pues la UE exige a sus socios no-comunitarios que caminen por la senda de la democratización de sus instituciones y, en consecuencia, Marruecos, como "Socio Preferente", deberá caminar por la misma si quiere seguir nutriéndose de los beneficios que los distintos Acuerdos Euro-mediterráneos firmados ${ }^{34}$ con la UE le han venido aportando.

34 Del 2008 hasta la actualidad, se han revisado continuamente el Acuerdo Euromediterraneo UE-Marruecos de 1996 con importantes ventajas para marruecos. En concreto, en marzo de 2012 entró en vigor el último Acuerdo Agrícola UE-Marruecos, que revisa los protocolos 1,2 y 3 del anterior, relativos a los precios de entrada, derechos ad valorem y contingentes para ciertos productos sensibles al mercado comunitario (tomate, alcachofas, pepinos, naranjas, clementinas, fresas, uvas, melocotones, calabacín y albaricoques). En general, salvo para estos productos, el proteccionismo de la UE respecto a los productos agrícolas marroquís ha desaparecido. 
